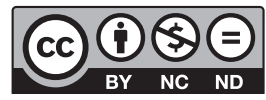

Estudos Teológicos foi licenciado com uma Licença Creative Commons Atribuição - NãoComercial - SemDerivados 3.0 Não Adaptada

http://dx.doi.org/10.22351/et.v60i3.3678

\title{
O CUIDADO HUMANO E O SENTIDO DA MORTE E DA VIDA ${ }^{1}$
}

\author{
Human care and the meaning of death and life
}

\section{Waldir Souza ${ }^{2}$ \\ Carla Corradi Perini ${ }^{3}$}

Resumo: A pesquisa bibliográfica, descritiva, objetiva discutir o cuidado, a morte e o sentido da vida nas perspectivas da antropologia filosófica, da teologia e da bioética. Sobretudo apresenta as obras de Edith Stein La strutura della persona umana (1933-2013), Ser Finito y Ser Eterno (1996) e Psicologia e scienze dello spirito (1922-1999). Certifica a história da morte e as transformações ocorridas na sociedade ocidental contemporânea, as mudanças de mentalidade e os comportamentos, assim como o afastamento do processo de morrer tradicionalmente familiar para o contexto das instituições hospitalares. A morte deixa de ser natural e torna-se selvagem, inimiga e revestida de tabus; a técnica assume lugar de importância nas decisões de vida e morte. A vida envolve mistério, requer responsabilidade, atenção, precaução, cautela e diligência. Para tanto, o cuidado, a vida e a morte necessitam de uma profunda argumentação que represente sua intrínseca relação. Tal como o sentido da vida, a existência humana no mundo, as relações e a capacidade de transcendência.

Palavras-chave: Vida. Morte. Antropologia filosófica. Teologia. Bioética.

Abstract: The bibliographical, descriptive research aims to discuss care, death and the meaning of life from the perspectives of philosophical anthropology, theology and bioethics. Above all presents the works of Edith Stein La structura della persona umana (1933-2013), Finite Being and Eternal Being (1996) and Psychology and Science of Spirit (1922-1999). It certifies the history of death and the transformations that occurred in contemporary western society, the changes in mentality and behaviors. Thus, as the departure from the process of dying traditionally familiar to the context of hospital institutions. Death ceases to be natural and becomes savage, enemy and tabbed; the technique assumes a place of importance in life and death decisions. Life involves mystery, requires responsibility, attention, caution, caution and diligence. Therefore, care, life and death need a deep argument that represents the connection of both and their intrinsic relationship. Such as meaning of life, human existence in the world, relationships and the capacity for transcendence.

Keywords: Life. Death. Philosophical anthropology. Theology. Bioethics.

1 O artigo foi recebido em 20 de agosto de 2019 e aprovado em 17 de junho de 2020 com base nas avaliações dos pareceristas ad hoc.

2 Doutor em Teologia. Professor do Programa de Pós-Graduação em Bioética e do Programa de Pós-Graduação em Teologia da PUCPR. Curitiba/PR, Brasil. E-mail: waldir.souza@pucpr.br

3 Doutora em Ciências da Saúde. Professora do Programa de Pós-Graduação em Bioética da PUCPR. Curitiba/PR, Brasil. E-mail: carla.corradi@pucpr.br 


\section{Introdução}

A vida, desde o início até o momento final, reveste-se de mistério, beleza, razão, emoção, perdas, alegrias, conquistas, derrotas, despedidas, encontros e transcendência. ${ }^{4}$ Os avanços científicos e tecnológicos redimensionaram o cenário social e as relações interpessoais, provocaram mudanças socioculturais que marcam a história contemporânea. As indagações da vida humana e da morte pressupõem caráter transdisciplinar, que compreende todo o respeito e a dignidade.

Ao privilegiar o pensamento de Edith Stein, sobretudo nas obras: La strutura della persona umana (1933-2013), elege a apresentação da estrutura humana, o corpo material, o corpo vivente e o espírito; Ser Finito y Ser Eterno (1950-1996), busca aprofundar a vida e a finitude; Psicologia e scienze dello spirito (1922-1999), a afabilidade do espírito humano. Para tanto, o cuidado, a vida e a morte se apresentam como uma profunda antropologia filosófica, teológica e bioética. No delineamento da existência, o ser humano passa pelo processo evolutivo, que tem início na formação embrionária, quando a vida se desperta no óvulo fecundado, coloca-se em crescimento e estruturação progressiva. Assim, a vida pressupõe absorção do corpo da mãe e de substâncias nutritivas que são elaboradas interiormente pelo organismo em evolução. Esse organismo cresce e se estrutura, não podendo ser considerado somente matéria, mas revestida e possuidora de alma. Sem dúvida, o ser humano compreende algo de objetivamente espiritual, ou seja, uma "forma" que configura a matéria. E essa "forma" é diferente daquelas consideradas coisas mortas. Conferindo ao indivíduo uma determinada configuração sensível, sendo que a força sofre movimentos próprios que produzem mudanças provenientes do externo em relação aos acontecimentos naturais. Essa "forma" também é depois a força vivente, que mantém unida uma multiplicidade de matérias (Stoffe), se estrutura de modo particular e fechado em si mesmo. Desta forma, as matérias são elaboradas interiormente e provenientes do externo, que as ordenam como um todo. Desta maneira, alma espiritual humana existe desde o primeiro instante da existência humana, ainda não desenvolvida em vida atual, pessoal e espiritual. Mas essa alma espiritual deve ser considerada como "forma" substancial do ser humano, ela é o princípio "formal” dominante que "forma" as substâncias constitutivas materiais em modo orgânico, animal, pessoal-espiritual. No curso desse processo "formativo" de desenvolvimento do indivíduo humano, que se dá gradualmente e efetua-se, determinando os diversos estados evolutivos. ${ }^{5}$

Para tanto, o núcleo ético de cuidado envolve o agir intencional na busca pelo bem da vida, que passa necessariamente pela orientação da ética para a existência. Nesse contexto entende-se a ética como produto do pensamento gerado pela interrogação da qualidade de vida, atribuída no sentido de bom. O cuidado enquanto manu-

4 PESSINI, L.; BARCHIFONTAINE, C.; BERTACHINI, L. (Orgs.). Bioética, cuidado e humanização. São Paulo: Loyola; Centro Universitário São Camilo, 2014. v. II, p. 209.

5 STEIN, Edith. La struttura della persona umana. A cura di Angela Ales Bello e Marco Paolinelli. Titolo originale: Der Aufbau der menschlichen Person. Traduzione Italiana di Michele Dambra D'Ambra. Roma: Città Nuova, 2013. p. 139-141. 
tenção e promoção da vida. Sendo assim, a responsabilidade é a condição de cuidado humano que perpassa toda a vida envolvendo a consciência e o valor de sentido.

A responsabilidade deriva do latim respondere, que significa responder a um chamado. Ser responsável é responder ativamente à necessidade do outro com dedicação e solicitude. Assumir a responsabilidade de cuidar de outra pessoa exprime a disponibilidade de fazer o possível e o necessário para o bem-estar do outro. Trata-se de atitude interna de ação externa que envolve o diálogo. ${ }^{6}$

Desta forma, pode-se compreender a atenção direcionada ao outro, aquela que exprime o agir ético e responsável. Em geral, representa a relação com o outro válida, e necessária em situações de cuidado específico, tal como nos cuidados paliativos, sobretudo na finitude, onde o rosto do outro comunica toda a sua vulnerabilidade. Mortari (2018) conceitua “o ser aí é ser-aí-com” no sentido amplo de sua concretude, pois o ser humano é codependente um do outro. Carente de cuidado desde o nascimento até a morte, fica evidente a todos os seres humanos essa condição essencial de cuidado, ou seja, envolvendo contínua troca de cuidados para que a vida se torne possível. $\mathrm{O}$ "cuidar uns dos outros" não é um ideal de existência, mas uma necessidade. Tal necessidade de cuidar revela a consciência e o senso de responsabilidade. Conferindo ao ser humano a vulnerabilidade, a fragilidade humana à sua condição de finitude e o cuidado comum a todos os seres. ${ }^{7}$

\section{Retomando o sentido do ser para retomar o sentido da vida}

O sentido da vida humana possibilita compreender a representatividade histórica da morte na sociedade ocidental contemporânea. Ao longo dos anos, vem apresentando transformações, mudanças de mentalidades e comportamentos com relação à finitude. Sendo possível esquadrinhar certa repulsa diante dessas tratativas. O processo de morrer deixa de ser tradicional e familiar, tornando-se institucionalmente hospitalar. A morte não é mais aceita como algo natural, desta forma a humanidade passa a considerá-la como: selvagem, inimiga e revestida de tabu. Isso tem gerado na humanidade uma desapropriação de sentido da vida, colocando em evidência as decisões, as responsabilidades, os sentimentos e os afetos em segundo plano e vem priorizando a técnica. É compreensível a evolução da técnica a serviço da humanidade, assim como é possível perceber que a tecnologia não supre o humano. A condição humana é a racionalidade, o sentir, o pensar e o agir, ou seja, o afastamento dessa condição acarreta o que chamamos hoje de desumanização. Portanto há que considerar a premissa da essência humana como possibilidade e condição de pensamento. Mediante esse raciocínio torna-se factível pensar o fenômeno da morte enquanto processo de lugar privilegiado na retomada de sentido da vida. ${ }^{8}$

\footnotetext{
6 MORTARI, Luigina. Filosofia do cuidado. São Paulo: Paulus, 2018. p. 134-136.

7 MORTARI, 2018, p. 141-142.

8 MAHFOUD, Miguel. Formação da pessoa e caminho humano: Edith Stein e Martin Buber. Memorandum 8, Belo Horizonte: UFMG; Ribeirão Preto: USP, 8, p. 55, abr. 2005. Disponível em: <http://www.fafich. ufmg.br/ memorandum/artigos08/mahfoud02.htm>. Acesso em: 07 maio 2019.
} 
Diante da complexidade da vida, primazia o pensamento de Edith Stein (19332013) em sua estruturação do ser humano como fundamento que denota a peculiaridade da vida e da morte, pois a morte somente é possível ao ser que vive. Define três estruturas complexas: o corpo físico, psique e espírito.

\section{Corporeidade}

Na verdade, em sua constituição corporal, o ser humano é uma coisa material, está submetido às leis que o coloca no âmbito dessa natureza. O ser humano é muito mais que um corpo material (Körper), é um corpo vivente (Leib), que permite a percepção do corpo matéria. Todos os corpos materiais estão ligados à psique e ao espírito para constituir a matéria que permite a vida humana. Se olharmos para as características do corpo humano, elas somam uma variedade de componentes materiais diferentes que desempenham papéis distintos em sua estruturação, visível na forma externa e na corporeidade. A anatomia humana sistematiza a estrutura material do corpo e seus diferentes componentes, onde somente é possível pensar a vida humana a partir de sua natureza corpórea. ${ }^{9}$

Para compreender a vida humana é preciso entender o "organismo vivente", ou seja, o corpo em sua forma material determinada pela realidade que mantém junto à interioridade, cuja forma exterior é formada pelo interno. Sendo um processo formativo e progressivo, o corpo passa pelo processo de transformação, considerando também a formação interna enquanto peculiar ao modo de ser do vivente. A formação interior que Edith Stein (1933-2013) elege é a indicação de Tomás de Aquino conhecida como "forma interior", também denominada de alma por Aristóteles. A "forma" interior qualifica o todo e é algo qualitativamente determinado pela espécie; é ao mesmo tempo a "força vital" que opera no processo de formação, dando "forma" a um material (Stoff), à matéria (Materie). Tudo aquilo que percebemos no mundo é matéria "formada", aquilo que diferencia os organismos das outras coisas materiais (coisas "mortas"), todo o processo de tomar "forma" é um processo vital. É impossível a matéria sem "forma" receber a existência, isso somente é concebido graças à "forma". Sendo que a "forma" vivente começa a agir em uma matéria já "formada" e por meio dela recebe a vida que é incorporada às novas matérias para estruturar progressivamente o organismo e dar a ele a "forma". Dependendo das condições materiais, a "forma" pode operar em maneira pura e sem obstáculos, e se conseguir, leva o organismo à sua forma mais completa e exemplar espécie. Por isso, no organismo, há um ponto máximo de desenvolvimento; depois desse processo de dar "forma", não mais pode acontecer e chegará ao declínio, ou seja, em um progressivo apagar da força "formante" e correspondente aumento da matéria não mais "formada" como matéria vivente, até a completa diminuição da vida. A "forma" vivente, a "alma" faz do corpo humano um organismo, quando nele não há mais vida, somente é considerado como coisa material, assim como as outras. Podemos compreender o corpo humano como

9 STEIN, 2013, p. 59-63 
organismo material que necessita do corpo vivente para viver ativamente, estruturar-se internamente e externamente. Quando o corpo vivente cessa todo o seu processo que chamamos vida, a morte se torna presente no real do corpo. ${ }^{10}$

\section{Psique}

A psique é conceituada por alma humana graças ao corpo vivente próprio de Tomás de Aquino. Reitera que cada ser humano tem seu próprio intelecto, porque cada um tem sua própria alma, cuja alma tem sua "forma" substancial, chegando a uma alma individual, única (singular), criada por Deus, então há uma "forma" individual do ser humano. A razão da sobrevivência das almas individuais que Tomás sustenta para a alma humana não pode ser fundada sobre o valor próprio da sua individualidade, existe uma possibilidade de substância da alma sem corpo vivente (assim como exige a fé), fato que a alma é uma substância para si mesma. Precedentemente encontra a partir da experiência vivida o acesso ao ponto de vista metafísico, a alma humana com sua estrutura pessoal e suas qualidades individuais, manifestada para nós como a "forma" de todo o indivíduo psicofísico. Habitualmente indicada também como "núcleo da pessoa" centro do ser, a estrutura estratiforme da pessoa humana no sentido de camadas que as constituem, sendo todas "formadas" a partir desse núcleo. Pode-se dispor da "formação" no sentido da vida psíquica atual que imprime no corpo vivente, ou seja, pelo que chamamos de "expressão". Isso comporta também uma modificação puramente corporal, podendo ser passageira ou duradoura no que tange os hábitos (rugas na testa, caminhar curvo); são todas transformações de algo "formado" que ocorrem ao longo de todo o curso da vida. Desta forma, pode-se compreender que tudo aquilo que é corporal é também psíquico, sendo que nesse dado momento não é no sentido de alma espiritual, mas naquele "psíquico inferior", cujas leis fundamentais consideradas são as capacidades de receber estímulos e de reações intuitivas. Da unidade da natureza humana faz parte tudo aquilo que nela penetra de "inferior" em maneira submetida à lei do espírito. A alma espiritual entra na unidade da natureza humana ocupando um lugar central e dominante, confere o caráter da personalidade e da autêntica individualidade que atravessa todos os níveis.

A alma humana apresenta as finas distinções entre a esfera psíquica e a espiritualidade no âmbito da análise da subjetividade. Desta maneira, ela aparece submetida à ação de diversas forças: a força sensível, que se apresenta em relação à apreensão dos dados sensíveis, dos impulsos sensíveis e da força espiritual totalmente nova e diferente da primeira. Pode abrir-se somente em colaboração com a força sensível, ou seja, tem suas raízes na natureza e isso justifica sua ligação entre natureza, corpo e psique. Esse lado corpóreo da psique corresponde àquele espiritual, mediante o qual a psique se abre ao mundo objetivo. Portanto o sustento da força espiritual da psique

10 STEIN, 2013, p. 65-66-111. 
individual pode vir de um mundo espiritual objetivo, seja ele constituído pelo mundo dos valores ou pela força espiritual dos outros sujeitos ou pelo espírito divino. ${ }^{1 / 12}$

Espírito

Considera o termo "espírito" (Geist) e seus vários sentidos na língua alemã, assim como também se evidencia nas expressões latinas intellectus, mens, spiritus, as quais são traduzidas pela palavra "espírito", sem exaurir o significado do termo. O espírito entendido no sentido de spiritus é o contraposto ao corpo (Körper), não entendido como corpo vivente (Leib), mas extenso a matéria. Spiritus originariamente corresponde à palavra grega pneuma, "sopro". A atribuição desse nome espírito deve-se ao conceito materialista dos primeiros filósofos gregos que representavam o espírito como "matéria" (Stoff) leve e sutil. Neste modo, colhe, contudo, algo que pertence à essência do espírito, a falta de fixação (ausência de vínculos espaciais), leveza e mobilidade. Um ser espiritual ligado a um corpo (como a alma humana) tem indiretamente um certo vínculo espacial. Quando um ser espiritual é livre de uma organização corporal-sensorial, é também livre do vínculo espacial indireto. Considerando a expressão "ser espiritual", o próprio termo não é indicativo de algo absolutamente simples e único, pode ser entendido no âmbito do ser ao qual pertencem entidades do tipo diferente. A alma indica o espírito ou "criatura espiritual", caracteriza a diferença de outras criaturas espirituais pelo fato de entrar no corpo material na unidade de uma única natureza. Diferentes dela são assim os ditos "puros espíritos", ou seja, criaturas sem corpo neste caso, os anjos e os demônios. Contudo, no sentido estrito, somente Deus é puro espírito, por isso colhe a essência do espírito na forma mais pura, não é fechado nem fixado ao limite do ser. ${ }^{13}$

O peculiar da alma como ser espiritual, ou seja, sua unidade de alma e corpo vivente é o caráter distintivo que mostra a diferença entre espíritos incorporais e puros espíritos. As almas humanas têm em comum os espíritos incorporais, a estrutura pessoal e o ser espiritual, que são substâncias que qualificam a "matéria espiritual" e a "forma individual". Aquilo que as torna "alma" as diferencia dos "puros espíritos", pelo fato de que elas são o "centro do ser", núcleo pessoal de uma natureza espiritual-corporal de uma pessoa psicofísica. A ligação com o corpo vivente é essencial para a alma, todavia a morte deve ser entendida como uma separação de corpo e alma. ${ }^{14}$ Essa arguição indica diversos fatores que marcam as questões de vida e morte já anunciadas. Assim, Edith Stein (1933-2013) retifica a concepção de morte considerada na antiga mitologia grega que continua a perdurar na época, sobretudo no cristianismo,

${ }^{11}$ STEIN, 2013, p. 112, 113, 114

12 STEIN, Edith. Psicologia e scienze dello spirito: contribute per una fondazione filosófica. Trad. Anna Maria Pezzella. Roma: Cittá Nuova, 1999. (Original publicado em 1922). p. 16.

${ }^{13}$ STEIN, 2013, p. 115-116.

${ }^{14}$ STEIN, 2013, p. 117-118. 
referente à crença em fantasmas. Outro fator é a separação entre corpo e alma, que sempre foi considerada como algo não natural. ${ }^{15}$

\section{Morrer com dignidade na perspectiva da bioética}

A vida é a condição da morte, ambas estão intrinsicamente ligadas. Para Edith Stein, a unidade da vida constitui o fundamento sobre o qual apoiamos legalmente para atuar no mundo. Conhecer as formas e as coisas pelas quais o mundo se desvela constitui parte de uma decisão de captar os significados que as mesmas possuem para os outros e para si mesmo. A compreensão das significações somente pode ser manifesta na interioridade humana, ou seja, pela captura viva de seu valor. Essa resposta que vem da interioridade exige objetivamente a participação da vontade e a incita a empreender e trabalhar de forma ativa. O conhecer, sentir, querer e o trabalhar não estão certamente separados por completo nem são independentes um dos outros, mas estão condicionados um pelo outro, porque são dependentes um dos outros, porém não formam uma unidade indissolúvel. Enquanto os movimentos independentes se deixam separar uns dos outros, os links objetivos nem sempre se realizam entre os elos. Logo, um olhar penetrante percebe o escurecimento do valor no caso, da simples natureza objetiva das coisas. Existe uma captação morta do valor que alcança inteligivelmente as significações das coisas na ausência de um princípio motor interno. Em que concerne à percepção vivente do valor, onde se encontra também um fracasso a respeito da vontade e da ação que apresenta debilidade, indecisão ou infidelidade. Esse processo difere entre as pessoas e em diferentes momentos. Quando a unidade da vida cessa, a ligação com o corpo vivente, a morte ocorre, todavia, entendida como separação do corpo e da alma. ${ }^{16 / 17}$

Nessa perspectiva de pensar a vida pela morte, ecoam os aportes da bioética como possibilidade de contemplar os questionamentos acerca do humano, ou seja, o fundamento absoluto da dignidade e autonomia, premissa do cuidado respeitoso, os quais reconhecemos como atitudes essenciais. ${ }^{18}$ A partir do objetivo fundamental das ciências da saúde, cujo favorecimento contempla o restabelecimento da integridade humana em todos os seus aspectos. A dignidade humana concebe pensar o ser humano dentro da realidade moral de direitos. Sendo vida e morte predicativos da dignidade que pressupõe contemplar medidas de conforto, intervenções éticas diante da dor e do sofrimento. A palavra "cuidado" desafia sua definição pela amplitude de expressão desenvolvida nos últimos trinta anos, sinônimo de hospice e cuidados paliativos. Surge oficialmente, na década de 1960, no Reino Unido, tendo como pioneira a médica Cicely Saunders. O trabalho dessa médica inicia o movimento dos cuidados

15 STEIN, 2013, p. 119.

16 STEIN, Edith. Ser finito y Ser eterno: ensayo de una ascensión al sentido del ser. 2. ed. Trad. A. P. Monroy. México: Fondo de Cultura Económica, 1996. (Original de 1934-1936, publicação póstuma em 1950). p. 409-410.

17 STEIN, 2013, p. 118.

18 PESSINI, Leocir; BARCHIFONTAINE, Christian de Paul. Problemas atuais de Bioética. São Paulo: Centro Universitário São Camilo; Loyola, 2014. p. 201-202. 
paliativos, que inclui a assistência, o ensino e a pesquisa. A criação do St. Christophers Hospice, em Londres, em 1967, é um marco nessa trajetória. ${ }^{19} / 20$

A prática dos cuidados paliativos baseia-se em princípios tais como: promover o alívio da dor e de outros sintomas desagradáveis; afirmar a vida e considerar a morte como processo normal da vida; não acelerar nem adiar a morte; integrar os aspectos psicológicos e espirituais no cuidado do paciente; oferecer um sistema de suporte que possibilite ao paciente viver tão ativamente quanto possível até o momento da morte; oferecer um sistema de suporte para auxiliar os familiares durante a doença do paciente e a enfrentar o luto; garantir abordagem multidisciplinar para focar as necessidades dos pacientes e seus familiares, incluindo acompanhamento no luto; melhorar a qualidade de vida e influenciar positivamente o curso da doença; implementar o mais precocemente possível, juntamente com outras medidas terapêuticas. ${ }^{21}$

No sentido de pensar o cuidado, a vida e a morte, Stein aponta a particularidade da vida e do espírito humano. O ser humano é possuidor de corpo, alma e espírito. Assim, o espírito humano se configura segundo a essência, possui a capacidade de sair de si mesmo pela "vida espiritual" e entrar no mundo que se abre a ele, sem perder nada de si mesmo. Emana não somente a sua essência como todo o produto real de uma maneira espiritual expressando o mesmo de forma inconsciente e ainda atua pessoal e espiritualmente. A alma enquanto espírito eleva a vida espiritual ao conhecimento de si mesmo. Porém o espírito humano está condicionado pelo superior e inferior imerso em um produto material, tal qual a alma é vista em sua forma corporal (Leibgestalt). A pessoa humana conduz e abarca seu corpo e sua alma. Sua vida espiritual se eleva de um fundo obscuro e estende-se como uma chama de vela, porém nutrida por uma matéria que brilha. E brilha sem ser absolutamente luz. $\mathrm{O}$ espírito humano é visível para si mesmo, porém não é todo transparente, pode iluminar outra coisa sem atravessá-la eternamente. $\mathrm{O}$ espírito conhece sua própria luz interior, sua vida presente e, em grande parte, o que tem antes de sua vida presente. Por isso o passado comporta lacunas e o futuro não pode ser previsto com probabilidade segura, mas parcialmente. Em grande parte, é incerto e indeterminado, ainda que nessa perceptível incerteza e indeterminação. Sua origem e sua meta são absolutamente inacessíveis, se permanecermos na consciência que depende da vida mesma sem ser ajudado pela experiência dos outros, ou seja, pelo pensamento intuitivo, pela racionalidade e pelas verdades de fé. Esses são os meios pelos quais o espírito puro não tem necessidade de conhecer a si mesmo. A vida imediata e certa do momento presente é a complacência que foge rapidamente e escapa por completo. Assim, toda a vida consciente não abarca pessoalmente o ser, mas se assemelha a uma superfície iluminada em seu ápice de profundidade sombria,

19 PESSINI, 2014, p. 199.

${ }^{20}$ DU BOULAY apud MELO, Maria Inês Amaro Assunção de; SOUZA, Waldir; PERETTI, Clélia. Cuidados paliativos e uma análise fenomenológica das vivências dos cuidadores de pacientes oncológicos. Revista Caminhos - Revista de Ciências da Religião, Goiânia, v. 17, p. 371-389, mar. 2019.

${ }^{21}$ ZOCCOLI, Thayana Louize Vicentini et al. Desmistificando cuidados paliativos. Brasília: Oxigênio, 2019. E-book. p. 8. 
manifestada pela superfície. Para conhecer o ser humano é necessário mapear e penetrar nessa profundidade. ${ }^{22}$

Essa relação de cuidado, vida e morte, e cuidados paliativos cogita demonstrar a complexidade que Stein retrata ao ser humano. Para tanto, compreender a interioridade da alma é importante para conhecer melhor o recurso distinto da alma humana. As faculdades de conhecimento asseguram, por assim, dizer o serviço exterior na morada da alma, permitem a penetração das coisas do mundo que vão ao encontro da pessoa. ${ }^{23}$ Sendo que os sentidos constituem a entrada para as coisas que assolam para baixo os sentidos. Desta maneira, o entendimento penetra como possuidor da profundidade espacial situada além do campo sensorial e na interioridade das coisas que não assolam para baixo os sentidos. Essa interioridade é acessível por meio da exterioridade sensível. A percepção sensível, como conhecimento intelectual, é uma unidade vivida de uma duração aproximadamente longa. O que desaparece da consciência não se perde para a alma, isso mantém e é possível recordar novamente toda a unidade vivida anterior. A alma humana é de suma importância para o corpo vivente, sendo a ruptura com o corpo material a morte propriamente dita. ${ }^{24}$

Portanto a morte somente pode ser considerada digna a partir da instância da vida em sua completude de significados, enquanto etapa natural de vida. Considerando os elementos constitutivos e essenciais na ética do cuidado, a compaixão, a humildade, a relação de confiança, que alude o modelo da ética das virtudes proposta por Pellegrino. ${ }^{25 / 26}$

Para tanto, cada ser finito não é inteligível por si, demanda a primeira entidade do infinito, cujos atributos correspondem à ideia de Deus. Considerando a evidência ontológica ao ser humano, e a finitude, a divindade demandada de Deus, sem essa relação com o ser divino o ser humano não seria inteligível. Essas questões não podem ser respondidas nem pela experiência nem pela evidência filosófica. ${ }^{27}$ Diante dessa completude, Stein recorda as verdades de fé, que envolvem a pesquisa filosófica para avaliar os resultados obtidos e/ou resolvê-los filosoficamente. Temos conhecimento da interioridade mais profunda da alma como a morada de Deus. Pela espiritualidade pura, essa interioridade é capaz de acolher o espírito de Deus. Por sua livre personalidade pode ser dado a ele o dom necessário para o acolhimento. A vocação de uma união com Deus é a vida eterna. ${ }^{28} \mathrm{O}$ ser humano é criado por Deus e a inteira humanidade como unidade constituída para uma única descendência. Cada alma humana

\footnotetext{
22 STEIN, 1996, p. 379-380.

23 STEIN, 1996, p. 449.

24 STEIN, 2013, p. 134.

${ }^{25}$ MARINO JUNIOR, R. Edmund Pellegrino: ícone da bioética cristã. In: PESSINI, Leocir; BARCHIFONTAINE, Christian de Paul; BERTACHINI, L. (Orgs.). Bioética, cuidado e humanização. São Paulo: Loyola; Centro Universitário São Camilo, 2014. v. III, p. 607-612.

${ }^{26}$ PELlEGRINO, E. D.; THOMASMA, D. C. Para o bem do paciente: a restauração da beneficência nos cuidados da saúde. São Paulo: Loyola, 2018. p. 169.

27 STEIN, 2013, p. 163.

28 STEIN, 1996, p. 518.
} 
(singular) é criada à imagem e semelhança de Deus. Sendo livre e responsável por aquilo que se torna. ${ }^{29}$

\section{Considerações finais}

Nessa perspectiva a vida do ser humano e seu espírito podem ser compreensíveis pelo mapeamento e pela penetração na profundidade. Edith Stein explicita em sua obra "Ser finito e Ser Eterno"30 a complexa relação da finitude e da eternidade como ponto crucial da humanidade. Desta maneira, esse estudo pretendeu apontar: qual o sentido da vida e da morte e sua representatividade? Qual a necessidade humana de ser cuidado? Essas inquietações que permeiam a vida humana revestem-se de beleza e mistério e, de certa forma, podem ser compreensíveis pela antropologia filosófica, pela teologia e pela bioética.

A estrutura humana nessa descrição de Stein está representada no âmbito da descrição do ser enquanto microcosmo unido por todos os diferentes níveis: o corpo matéria, o corpo vivente e o ser espiritual. ${ }^{31}$

O cuidado, a vida e a morte são experimentados na existência humana pela espiritualidade, que corresponde à abertura ao interno e externo. A "forma" originária do saber, própria do ser e da vida espiritual, não é um saber que chega depois do reflexivo. A vida espiritual é um saber igualmente originário dos outros e de si mesmo. A sabedoria de si é a abertura ao interno e o saber do outro é a abertura ao externo. Essa distinção justifica a necessidade de ser cuidado por si mesmo e pelo próximo; essa compreensão retrata os cuidados paliativos. ${ }^{32}$

Por isso é possível para a ciência explicar a morte pelo viés da vida ${ }^{33}$, revelando ao ser humano o temor da morte pelo não vivido, ou seja, o medo da morte é na realidade o medo da vida. O ser humano que protela seus projetos vive lamentos do passado, angústias, não percebendo o tempo passar, nem mesmo suas próprias fragilidades.

O tempo pertence à ordem da criação e permite ao finito separar-se do eterno de maneira completamente característica. A significação de finitude não tem nem começo nem fim, ao mesmo tempo, a delimitação material da multiplicidade das unidades do ser divino está ordenada em direção à relação temporal. Assim, a antítese do ser essencial e do ser real e sua possibilidade estão determinadas em um duplo sentido: ser fundado do real temporal no interior da essência do ser essencial das unidades significativas delimitadas de "possibilidade essencial", onde a possibilidade é o primeiro grau destinado a uma realidade mais alta, as "potencialidades frente à atualidade", justificando o modo de ser inferior do ser temporal. O ser temporal real não é uma realidade acabada "ato puro", se não uma realização de possibilidades essenciais submetidas a um princípio e a um progresso. A oposição do ser autônomo

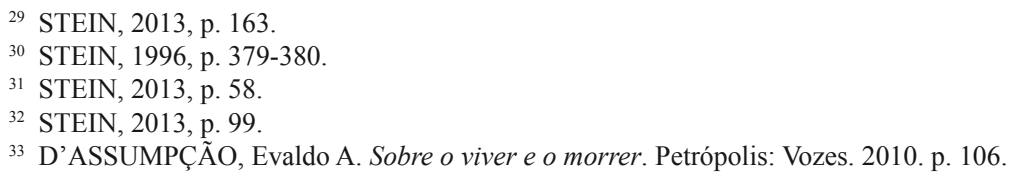


e do ser dependente faz parte disso. O princípio da realização é um passo da possibilidade essencial da realidade temporal ou a entrada na existência temporal. A relação progressiva pertence a uma entidade que leva em si possibilidades, todavia não realizadas, algo que não deveria ser, mas o que está determinado em seu dever de ser, ou seja, o seu desenvolvimento está determinado antecipadamente. O real temporal é um ser colocado em si mesmo, é uma determinação da essência. Suas possibilidades não realizadas "potenciais" estão fundadas em si, ou seja, o seu ser participa do próprio ser. Esse é o próprio passo a um grau superior do ser. A separação da "forma" e do "conteúdo" faz parte do ser finito, enquanto ser delimitado objetivamente. A forma vazia é a linha objetiva de delimitação que permite ao ser separar-se exteriormente de outras coisas e graças a essa forma dispõe interiormente em modo estrutural as partes constitutivas separadas objetivamente. ${ }^{34}$

O que determina a plenitude no interior da forma é o sentido (a ideia). Em Deus unicamente pode-se conceber o sentido e a plenitude, ambas em perfeita unidade. A separação do ser na criação condiciona uma distinção dos diversos campos do ser segundo a forma e a matéria. A matéria corporal é uma plenitude espacial indeterminada e a matéria espiritual a plenitude de vida indeterminada. As formas corporais se transformam ou transformam sua matéria situada nos espaços em direção ao mundo das coisas corporais. As formas espirituais dão configuração à sua plenitude de vida em direção ao interior de um reino espiritual, de pessoas e de atos que constituem todos em um conjunto funcional espiritual. Mas o mundo espiritual e o mundo corporal não estão justapostos, sem nenhuma relação recíproca. O que não é espírito puro é um produto informado pelo espírito, quer seja imediatamente pelo espírito divino ou mediatamente pelas formas criadas a partir da matéria que os correspondem. Nos produtos naturais, a matéria e a forma estão ligadas a uma unidade de essência. As obras humanas supõem tais produtos naturais, que recebem um sentido novo por uma ação que vem do exterior. Assim, formam uma unidade de sentido e de vida, os produtos criados são imagens da essência divina. Portanto caracterizamos o ser finito enquanto abordagem ao ser divino. Tal tentativa somente é possível pela síntese do ser divino próprio, estendendo as criaturas ao Criador e arquétipo do finito que é condicionado até o infinito. ${ }^{35}$ Aquilo que o ser humano tem de mais profundo e próprio deve-se somente a Deus, como também tudo aquilo que recebe na comunidade terrena. Deus estabelece a medida das obrigações que cada ser humano possui nas comunidades. Sendo assim, o fim último do ser humano é a vida eterna. ${ }^{36}$

Considerando a bioética enquanto estudo sistemático da conduta humana na área das ciências da vida e dos cuidados em saúde, os cuidados paliativos abarcam a proposta de oferecer assistência e cuidar do sofrimento humano. Em oposição à prática tecnológica e institucionalizada, que exclui o ser humano das decisões relativas

\footnotetext{
34 STEIN, 1996, p. 369-370.

35 STEIN, 1996, p. 431.

36 STEIN, 2013, p. 161-165.
} 
à vida e à morte ${ }^{37}$ Essas decisões referidas ao sentido da vida e da morte esbarram na complexidade da singularidade humana e na profundidade que este estudo abarca nessa perspectiva teórica. Para tanto, cuidado, vida e morte apresentam uma profunda antropologia filosófica, teológica e bioética.

\section{Referências}

D’ASSUMPÇÃO, Evaldo A. Sobre o viver e o morrer. Petrópolis: Vozes, 2010.

MAHFOUD, Miguel. Formação da pessoa e caminho humano: Edith Stein e Martin Buber. Memorandum 8, Belo Horizonte: UFMG; Ribeirão Preto: USP, 8, p. 52-61, abr. 2005. Disponível em: <http://www.fafich.ufmg.br/ memorandum/artigos08/mahfoud02.htm>. Acesso em: 07 maio 2019.

MARINO JUNIOR, Raul. Edmund Pellegrino: ícone da bioética cristã. In: PESSINI, L.; BARCHIFONTAINE, C.; BERTACHINI, L. (Orgs.). Bioética, cuidado e humanização. São Paulo: Loyola; Centro Universitário São Camilo, 2014. v. III, p. 607-612.

MELO, Maria Inês Amaro Assunção de; SOUZA, Waldir; PERETTI, Clélia. Cuidados paliativos e uma análise fenomenológica das vivências dos cuidadores de pacientes oncológicos. Revista Caminhos - Revista de Ciências da Religião, Goiânia, v. 17, p. 371-389, mar. 2019. Disponível em: $<$ http://seer.pucgoias.edu.br/index.php/caminhos/article/view/6817>. Acesso em: 18 ago. 2019. MENEZES, Rachel Aisengart. Em busca da boa morte. Antropologia dos Cuidados Paliativos. Rio de Janeiro: Fiocruz; Garamond, 2004.

MORTARI, Luigina. Filosofia do cuidado. São Paulo: Paulus, 2018.

PELLEGRINO, E. D.; THOMASMA, D. C. Para o bem do paciente: a restauração da beneficência nos cuidados da saúde. São Paulo: Loyola, 2018.

PESSINI, Leocir; BARCHIFONTAINE, Christian de Paul. Problemas atuais de Bioética. São Paulo: Centro Universitário São Camilo; Loyola, 2014.

PESSINI, Leocir; BARCHIFONTAINE, Christian de Paul; BERTACHINI, L. (Orgs). Bioética, cuidado e humanização. São Paulo: Loyola; Centro Universitário São Camilo, 2014. v. III.

STEIN, Edith. La struttura della persona umana. A cura di Angela Ales Bello e Marco Paolinelli. Titolo originale: Der Aufbau der menschlichen Person. Traduzione Italiana di Michele Dambra D’Ambra. Roma: Cittá Nuova. 2013. (Original publicado em 1933).

STEIN, Edith. Psicologia e scienze dello spirito: contribute per una fondazione filosófica. Trad. Anna Maria Pezzella. Roma: Cittá Nuova, 1999. (Original publicado em 1922).

STEIN, Edith. Ser finito y Ser eterno: ensayo de una ascensión al sentido del ser. 2. ed. Trad. A. P. Monroy. México: Fondo de Cultura Económica, 1996. (Original de 1934-1936, publicação póstuma em 1950).

ZOCCOLI, Thayana Louize Vicentini et al. Desmistificando cuidados paliativos. Brasília: Oxigênio, 2019.356 p. (e-book). Disponível em: <https://drive.google.com/file/d/1pr_6xzIWR4ELDro_ TvVqQPNe1A41MUOY/view>.

${ }^{37}$ MENEZES, Rachel Aisengart. Em busca da boa morte. Antropologia dos Cuidados Paliativos. Rio de Janeiro: Fiocruz; Garamond, 2004. p. 20. 